\title{
ОСОБЕННОСТИ ЛИЧНОСТНОЙ ИДЕНТИЧНОСТИ «ПОСТОЯННЫХ» $И$ «ВРЕМЕННЫХ» МИГРАНТОВ
}

\section{FEATURES OF THE PERSONAL IDENTITY OF "PERMANENT" AND "TEMPORARY" MIGRANTS}

A. Chernov

Summary: Personal identity of migrants is one of the factors of their successful adaptation to new cultural and social conditions for them. An important characteristic of the personal identity of migrants is the level of coherence of value and semantic components, as well as self-relation. The study recorded a higher level of consistency of personal identity of the «permanent» migrants, which indicates its distinctness to the time factor in a new environment for migrants. The content of personal identity is interconnected with psychological phenomena, revealing the features of the experiences of migrants of intrapersonal conflict. This relationship is different in different ways in the groups of "temporary" and "permanent" migrants. An important trend can be considered that in permanent migrants with the accumulation of interaction experience with a new social medium for them, the increase in the coherence of personal identity is associated with a more apparent manifestation of sociocentric orientation, as a method of resolving the intrapersonal conflict.

Keywords: temporary migration, constant migration, personal identity, coherence of personal identity, intrapersonal conflict.

\section{Введение: теоретическое обоснование исследования}

культур исциплинарные и тематические аспекты изучения миграции и мигрантов весьма разнообразны. Предметом исследования выступают 作, политические, экономические, демографические и иные факторы, воздействие которых на миграционные процессы анализируется с разных методологических позиций и с привлечением специфических эмпирических данных.

Отмечается, что психологическая адаптация опосредована этнической идентичностью, то есть восприятием, пониманием и оцениванием индивидом своей принадлежности к этнической общности [8;9]. При этом этническая идентичность, как переживание отношения человека и его этнической среды, не может быть изоли-

\author{
Чернов Александр Юрьевич \\ Д.псх.н., дочент, с.н.С., Волгоградский государственный \\ университет; nрофессор, РАНХГИС \\ (Волгоградский филиал) \\ achernov1@yandex.ru
}

Аннотация: Личностная идентичность мигрантов является одним из факторов их успешной адаптации к новым для них культурным и социальным условиям. Важной характеристикой личностной идентичности мигрантов выступает уровень согласованности ценностных и смысловых компонентов, самоотношения. В исследовании зафиксирован более высокий уровень согласованности личностной идентичности у «постоянных» мигрантов, что свидетельствует о ее опосредованности фактором времени, проведенным в новой для мигрантов среде. Содержание личностной идентичности взаимосвязано с психологическими феноменами, раскрывающими особенности переживания мигрантами внутриличностного конфликта. Эта взаимосвязь по-разному проявляется в группах «временных» и «постоянных» мигрантов. Важной тенденцией можно считать то, что у постоянных мигрантов с накоплением опыта взаимодействия с новой для них социальной средой рост согласованности личностной идентичности сопряжен с более очевидным проявлением социоцентрической ориентации, как способа разрешения внутриличностного конфликта.

Ключевые слова: временная миграция, постоянная миграция, личностная идентичность, согласованность личностной идентичности, внутриличностный конфликт.

рована от личностной идентичности, которая трактуется как отношение человека к самому себе, формирующегося в ходе социального взаимодействия, становясь, таким образом, компонентом самосознания [10]. Личностная идентичность конструируется в формальных проявлениях психолого-феноменологического комплекса, составляющими которого являются общение, опыт и роли, порождающие идентичность, а также речь, через которую идентичность выражается [14; 22].

Личностная идентичность связана с множеством взаимодействий и отношений человека. Таким образом, личностная идентичность мигрантов есть продукт интерпретации ими ситуаций, с которыми они сталкиваются и поведения «действующих лиц», с которыми вступают во взаимодействие [21]. С. Бонева и И. Фризе указывают на наличие «иммиграционного синдрома» как одного из факторов, определяющих миграционное поведение. В

Работа выполнена при финансовой поддержке РФФИ и администрации Волгоградской области (грант № 19-413340015 p_a) 
частности, опираясь на результаты собственных исследований, авторы показывают, что его содержание включает специфическое сочетание мотивации достижений и мотивации аффилиации [16]. Ряд авторов указывают на значимость таких процессов, как «самосбывающиеся пророчества», «стигматизация», «угроза сложившимся стереотипам» [20].

Личностная идентичность не изолирована от личности в целом. Она взаимосвязана с конструктами, характеризующими индивидуальные особенности субъекта, которые, в свою очередь являются индикаторами его психологической адаптированности и переживания психологического благополучия. Один из таких индикаторов - внутриличностный конфликт, актуализирующий противоречия различных психических образований, затрагивающий, в том числе, сферу персональной идентичности. Как отмечает Е.Б. Фанталова, состояние внутреннего конфликта - это, прежде всего, со стояние «разрыва» в системе «сознание-бытие», а именно разрыва между потребностью в достижении внутренне значимых ценностных объектов и возможностью такого достижения в реальности $[2 ; 6 ; 8 ; 11]$.

Таким образом, можно говорить, что применительно к мигрантам, взаимосвязь их личностной идентичности с проявлениями внутриличностного конфликта представляет актуальную научную проблему, без решения которой важные аспекты их адаптации остаются без ответа. В связи с этим выявление особенностей такой взаимосвязи составляет предмет нашего исследования. В качестве основной гипотезы выдвигается предположение о ее дискретном характере, являющимся следствием различий опыта, полученного мигрантами во время проживания в новой для них культурной среде.

\section{Метод}

Подходы к изучению личностной идентичности (психоаналитический, когнитивный, субъектно-деятельностный и др.) учитывают ее разные стороны и поэтому предполагают использование специфических средств диагностики ее видов, форм, содержания. Общим принципом является опора на системную организацию параметров личностной идентичности. Этот принцип реализуется в психосемантической направленности диагностики личностной идентичности. Один из вариантов реализации этого принципа представлен В.Б. Никишовой и Е.А. Петраш в разработанной ими методике исследования личностной идентичности. В качестве критерия оценки личностной идентичности авторами предложен показатель согласованности\рассогласованности ее структурной организации в психосемантическом выражении [5]. Каждая из степеней согласованности (высокая, средняя, низкая, очень низкая) имеет собственное содержательное наполнение с точки зрения социально- психологической адаптации, самоотношения, ценностных ориентаций, самостоятельности.

Отдельную проблему представляет диагностика внутриличностного конфликта. Здесь тоже обнаруживается несколько подходов. Например, Н.А. Падымов и Э.Э Сульчинская предлагают использовать комплекс методик, исследующих терминальные ценности, мотиваторы психологической активности, ценностные ориентации личности с тем, чтобы выявить содержание внутриличностного конфликта [6]. Похожий подход реализован О.О. Шемякиной, которая называет устойчивые факторы внутриличностного конфликта: «самостоятельность», «эмоциональная устойчивость», «самооценка актуальной жизнедеятельности», «психическая напряженность», «тенденций поведения» [13].

Более специфичной является методика «Диагностика внутреннего конфликта» Е.Б. Фанталовой, включающая инструменты для измерения доминирующих ценностей и конфликтов личности и способов их эмоциональной переработки [12]. В этом же ряду целесообразно упомянуть «Тест по выявлению уровня внутриличностной конфликтности» А.И. Шипилова. С ее помощью определяются наиболее конфликтные компоненты структуры внутреннего мира личности: мотивационный компонент, компонент долженствования, компонент самооценки [1]. Для целей нашего исследования наиболее приемлемой показательной является тест внутриличностных конфликтов Лаутербаха, выявляющий степень осознания респондентом психологических механизмов своих внутренних проблем и степени выраженности внутриличностного конфликта [3; 4].

Таким образом, исследование осуществлялось в несколько этапов. На первом этапе осуществлена операционализация переменных и выбор релевантных целям исследования диагностических методик. Второй этап заключался в сборе эмпирических данных и их статистического анализа. Выборку респондентов составили мигранты из стран Средней Азии, Казахстана и Азербайджана, проживающих в регионе Нижнего Поволжья (Волгоградская и Астраханская области). В соответствии с гипотезой исследования, респонденты были разбиты на две группы. Первую составили мигранты, прибывшие в регион для периодических сезонных работ на срок менее полугода («временная миграция), вторую - люди, проживающие в регионе на постоянной основе не менее 3 лет («постоянная миграция»). Всего в исследовании приняли участие 160 респондентов (78 человека, представляющих группу постоянных мигрантов и 82 человек из группы временных мигрантов). Все респонденты владели русским языком в достаточной для заполнения бланковых методик степени. Третий этап исследования состоял в интерпретации и обобщении полученных эмпирических результатов. 


\section{Результаты исследования}

В Таблице 1 приведены результаты использования методики В.Б. Никишовой и А.Е. Петраш Е.А. исследования личностной идентичности.

Результаты описательной статистики свидетельствуют о статистически значимых различиях показателей личностной идентичности у групп временных и постоянных мигрантов. Наиболее отчетливо различия видны в соотношении количества респондентов с «высокими» (13\% и $22 \%$ ) и «низкими» (28\% и 15\%), и «очень низкими» (12\% и 9\%) оценками. В группе временных мигрантов количество респондентов с «низкими» и «очень низкими» оценками приблизительно в три раза превышает количество респондентов с «высокими» оценками. Содержательно, это может быть описано как тенденция к рассогласованности личностной идентичности в этой группе респондентов, которая в качестве последствий проявляется в низком уровне социально-психологической адаптации, неустойчивости самоотношения и системы ценностных ориентаций, среднем или низком уровне рефлексивности и самостоятельности. В группе постоянных мигрантов количество респондентов с «высокими» и «низкими», и «очень низкими» показателями согласованности идентичности примерно одинаково, однако с учетом относительно большого количества средних оценок можно говорить о тенденции к согласованности личностной идентичности. У постоянных мигрантов в целом более высокий уровень социально-пси- хологической адаптации, позитивное самоотношение, устойчивая система ценностных ориентаций.

Интерпретация полученных результатов связана с учетом факторов, которые оказывают влияние на адаптацию мигрантов. Среди них называются экономические и культурные факторы, а также фактор этнической идентичности, проявляющийся в приверженности своей этнической группе, оценке того, насколько принадлежность к ней благоприятна для человека. Вместе с тем этническая идентичность пластична, может изменяться, сообразно обстоятельствам. При взаимодействии и иной социальной и культурной средой как этническая, так и личностная идентичность опосредована восприятием человеком своих возможностей в ней, переоценкой ценностных и поведенческих стереотипов, процессами целеполагания. Это опосредование требует накопления опыта взаимодействия с новой средой, и, следовательно, проявления действия фактора времени. Чем меньше времени человек проводит в новой для него культурной среде, тем прочнее остается этническая идентичность, компенсирующая личностную идентичность, которая тогда характеризуется признаками «рассогласования». И наоборот, личностная идентичность становится более «согласованной», когда с течением времени для человека причин, по которым ему целесообразно идентифицировать себя с этнической группой становится меньше, особенно если это касается членства в группе «меньшинства».

Таблица 1.

Результаты описательной статистики, полученные при использовании методики исследования личностной идентичности

\begin{tabular}{|c|c|c|c|c|c|c|c|}
\hline \multirow[t]{2}{*}{ Тип миграции } & \multirow[t]{2}{*}{ N } & \multirow{2}{*}{$\begin{array}{l}\text { Средние } \\
\text { значения }\end{array}$} & \multirow{2}{*}{$\begin{array}{l}\text { Стандартное } \\
\text { отклонение }\end{array}$} & \multicolumn{4}{|c|}{$\begin{array}{l}\text { Согласованность личностной идентичности } \\
\text { (накопленный процент) }\end{array}$} \\
\hline & & & & Высокая & Средняя & Низкая & Очень низкая \\
\hline Временная миграция & 82 & 27,5 & 10,24 & $13 \%$ & $47 \%$ & $28 \%$ & $12 \%$ \\
\hline Постоянная миграция & 78 & 32,8 & 7,94 & $22 \%$ & $54 \%$ & $15 \%$ & $9 \%$ \\
\hline Всего & 160 & 39,9 & 9,09 & & & & \\
\hline
\end{tabular}

Примечание*. Проверка на нормальность распределения (тест Колмогорова-Смирнова) р>0,05

Примечание ${ }^{* *} t$-критерий Стьюдента р <0,05

Таблица 2.

Взаимосвязь согласованности личностной идентичности и параметров внутриличностного конфликта и постоянных и временных мигрантов

\begin{tabular}{|c|c|c|c|c|c|c|}
\hline \multirow{3}{*}{ Внутриличностный конфликт } & \multicolumn{3}{|c|}{ Временные } & \multicolumn{3}{|c|}{ Постоянные } \\
\hline & \multicolumn{6}{|c|}{ Согласованность личностной идентичности } \\
\hline & B & c & H & B & c & H \\
\hline Стремление к независимости/желание получить помощь & $0,413^{* *}$ & & & $-0,505^{* *}$ & $0,311^{*}$ & $0,261^{*}$ \\
\hline Стремление к достижению успехаІстрах неудачи & & $-0,269$ & & $-0,415^{* *}$ & & $0,301^{*}$ \\
\hline Собственные поступки/выполнение социальных норм & & & & $-0,377^{*}$ & & \\
\hline Достижения/отсутствие настойчивости & & & $0,303^{*}$ & & & $0,412^{*}$ \\
\hline Норма|прявление агрессии & $-0,459^{* *}$ & & & & & 0,293 \\
\hline
\end{tabular}


Вместе с тем, наряду с общей тенденцией необходимо остановиться на некоторых специфических для разных групп респондентов взаимосвязях между показателями личностной идентичности и теоретически связанными с ней конструктами «внутриличностный конфликт» «типичные эмоциональные состояния». Таблица 2 содержит результаты корреляционного анализа, показывающего значимые взаимосвязи «высокой», «средней» и «низкой» согласованности личностной идентичности с параметрами внутреннего конфликта, измеренными посредством методики В. Лаутербаха.

Во-первых, следует отметить общие для обеих групп взаимосвязи личностной идентичности и параметров внутриличностного конфликта. Значимые корреляции между этими переменными выявлены в отношении таких параметров внутриличностного конфликта как «стремление к независимости/желание получить помощь», «стремление к достижению успеха \страх неудачи», «собственные поступки/нормы», «достижения/отсутствие настойчивости», «норма\проявление агрессии». Обобщая, можно сказать, что для «постоянных» и «временных» мигрантов характерны все виды внутриличностных конфликтов: мотивационные, поведенческие, аффективные. Вместе с тем, очевидна и специфика проявления взаимосвязи согласованности личностной идентичности с различными параметрами внутриличностного конфликта в разных группах респондентов. Во-первых, различия касаются людей, характеризующихся высокой согласованностью личностной идентичности. У «постоянных» мигрантов с высокой согласованностью личностной идентичности наблюдается «желание получить помощь» $\left(r=-0,505^{* *}\right)$, «страх неудачи» $\left(r=-0,414^{* *}\right)$, «ориентация на выполнение социальных норм» $\left(r=-337^{*}\right)$. У «временных» мигрантов с высокой согласованностью личностной идентичности можно предполагать выраженность «стремления к независимости» $\left(r=0,413^{* *}\right)$ и «проявление агрессии» $\left(r=-0,459^{* *}\right)$. Можно заключить, что высокий уровень согласованности личностной идентичности у «временных» и «постоянных» мигрантов имеет различные качественные характеристики»: в первом случае в большей степени выражены эгоцентрические, а во втором - социоцентрические тенденции.

Далее, обращает на себя внимание факт отрицательной направленности взаимосвязи параметров внутриличностного конфликта у людей с высокой и низкой согласованностью личностной идентичности в группе «постоянных» мигрантов. Высокая согласованность связана с «желанием получить помощь» $\left(r=-0,505^{* *}\right)$ и «страхом неудачи» $(r=-0.415)$, а низкая согласованность - со стремлением к независимости $\left(r=0,261^{*}\right)$, «стремлением к достижению» $\left(r=0,301^{*}\right)$, так же как у «временных мигрантов с высокой согласованностью. «Похожесть» содержания внутриличностного конфликта у временных и постоянных мигрантов с высокой и низкой со- гласованность личностной идентичности объясняется, на наш взгляд, особенностями мотивации на разных этапах вхождения в новую социальную среду. На ранних этапах согласованность личностной идентичности подвергается риску, что влечет преобладание эгоцентрической ориентации. Со временем, у «постоянных» мигрантов личностная идентичность стабилизируется, и на первый план выходят социоцентрические мотивы. У «временных» мигрантов в силу ограниченности времени пребывания, такой переход не осуществляется. То есть в стабилизации личностной идентичности и связанными с ней качественными характеристиками внутриличностного конфликта вновь заметную роль играет временной фактор.

\section{Зак^ючение}

Интерпретация полученных взаимосвязей личностной идентичности, проявления внутриличностного конфликта в разных группах мигрантов позволяет соотнести их с результатами, полученными в ряде теоретических и эмпирических исследований миграции. [15; 18; 19$].$

Во-первых, современные теории миграции рассматривают этническую и личностную идентичность как взаимодополняющие феномены. Они представляют собой концептуальное пространство, необходимое для достижения более глубокого понимания психологии мигрантов и анализа различий между психологическими и иными ее измерениями. Вместе с тем, личностная и этническая идентичности не тождественны. С функциональной точки зрения, личностная идентичность обеспечивает психологический процесс индивидуации, ее вектор направлен в сторону постепенного преодоления границ этнической идентичности, что само по себе является одним из условий адаптации к изменившимся для мигрантов культурным и социальным стандартам. В связи с этим, например, С. Дайаль применительно к мигрантам использует термин «двойное сознание» для обозначения их чувствительности к разным возможностям выбора адаптационных практик определяя его как «чувство постоянного взгляда на себя глазами других, дестабилизации пограничных зон культур, как разломы субъекта, которые сопротивляются ложным утешительным идентификациям и его воплощениям» [17].

«Изобретение» новой личностной идентичности неминуемо порождает процессы согласования и рассогласования ее компонентов. Это, в свою очередь, обусловливает появление вариантов переживания внутриличностных конфликтов и возникновение типичных эмоциональных состояний, а также специфических для разных групп мигрантов взаимосвязей между ними и степенью согласованности или рассогласованности личностной идентичности. Специфика взаимосвязи по- 
зволяет учитывать фактор времени, которое мигранты провели в новой для них культурной и социальной среде. Он выступает как объяснительный принцип различий выявленных взаимосвязей в группах «постоянных» и «временных» мигрантов.

Таким образом, проведенное исследование позволяет сформулировать следующие выводы:

1. Важной характеристикой личностной идентичности мигрантов является степень ее согласованности как показатель успешности адаптации к новым для них культурным и социальным условиям. Содержательное наполнение личностной идентичности мигран- тов характеризуется уровнем согласованности ее психологических и социально-психологических составляющих и изменяется с течением времени, проведенного в новой для них среде.

2. Динамика стабилизации личностной идентичности осуществляется в направлении от преобладания эгоцентрических мотивов к преобладанию социоцентрических мотивов.

3. Высокий уровень согласованности личностной идентичности мигрантов предопределяет специфику переживания внутриличностного конфликта и способствует возникновению благоприятных типичных эмоциональных состояний.

\section{ЛИТЕРАТУРА}

1. Анцупов А.Я., Шипилов А.И. Конфликтология. - СПб.: Питер, 2015. - С. 504-509.

2. Гуров А.В. Внутриличностный конфликт и сопровождающие его психические состояния \Вестник ТвГУ. Серия «Педагогика и психология». - 2017. Выпуск 2. - С. 56-61.

3. Карвасарский Б.Д. Клиническая психология. - М., 2004 г. - 553 с.

4. Куликов Л.В. Руководство к методикам диагностики психических состояний, настроений и сферы чувств. Описание методик, инструкции по применению. - СПб.: СПГУ, 2003. - 228 с.

5. Никишова В.Б., Петраш Е.А. Методика исследования личностной идентичности: методология и технология стандартизации|ЏНаучные ведомости. Серия Гуманитарные науки. - 2014.- № 13 (184). - Выпуск 22. - С. 354-361.

6. Подымов Н.А., Сульчинская Э.Э. Проблема диагностики внутриличностных конфликтов в ценностно-мотивационной сфере // Научный результат. Педагогика и психология образования. - 2018. -Т. 4. - №3. С. 71-79.

7. Прохоров А.О., Валиуллина М.Е., Габдреева Г.Ш., Гарифуллина М.М., Менделевич В.Д. Психология состояний: учеб. пособие / под ред. А.О. Прохорова. М.: Изд-во «Когито-Центр», 2011. 624 с.

8. Репринцев А.В., Сухоруков И.С. Формирование этнокультурной идентичности подростков и юношества как проблема современной психологии и социальной педагогики\ Научные ведомости. - Серия Гуманитарные науки. - 2017. - № 7(256) -. Выпуск 33. - С. 142-149.

9. Стефаненко Т.Г. Этнопсихология. - М.: Аспект Пресс, $2004-$ С. 127.

10. Труфанова Е.О. Идентичность и Я//Вопросы философии. - 2008- № 6- С. 95

11. Фанталова Е.Б. Диагностика и психотерапия внутреннего конфликта. - Самара: Издательский дом БАХРАХ-М, 2001 - 128 с.

12. Фанталова Е.Б. Диагностика ценностей и внутренних конфликтов в общей и клинической психологии ІККлиническая и специальная психология. - 2013. - №1. - C. 5-23.

13. Шемякина 0.0. Исследование внутриличностных конфликтов юношеского этапа развития \Электронный журнал «Психологическая наука и образование» www.psyedu.ru / ISSN: 2074-5885 / E-mail: psyedu@mgppu.ru 2012, №2.

14. Шнейдер Л.Б. Личностная, гендерная и профессиональная идентичность: теория и методы диагностики. - М.: Московский психолого-социальный институт, 2007. $-128 \mathrm{c}$.

15. Arango, J. Explaining migration: A critical viewIVInternational Social Science Journal. - 2000. - № 52(165)- pp. $283-296$.

16. Boneva B.S., Frieze I.H. Toward a Concept of a Migrant Personalityl IJournal of Social Issues. 2001. - Vol. 57. -№ 3. - pp. $477-491$

17. Dayal S. Diaspora and Double Consciousness। Ihe Journal of the Midwest Modern Language Association. 1996. - Vol. 29. - №1 (Spring).- pp. 46-62.

18. de Haas, H. The internal dynamics of migration processes: A theoretical inquiry\\ Journal of Ethnic and Migration Studies. 2010. - № 36(10) - pp. $1587-1617$.

19. de Haas, H. Migration and development: A theoretical perspectivel International Migration Review. - 2010. - № 44(1). - pp. $227-264$.

20. Madon M. Guyll S, Scherr K. The Potential Roles of Self-Fulfilling Prophecies, Stigma Consciousness, and Stereotype Threat in Linking Latino/a Ethnicity and Educational Outcomes IVJournal of Social Issues. 2001. - Vol. 57. № 3. - pp. 477-491.

21. Prilleltensky I. Migrant Well-Being is a Multilevel, Dynamic, Value Dependent Phenomenon IICommunity Psychol. - 2008. - № 42. - pp. 359 -364.

22. Stets J.E., Michael M.H 2004. Verification across multiple identities: The role of status|lSocial Psychology Quarterly. - 2004. - № 67. - pp. 155 -171.

(с Чернов Александр Юрьевич (achernov1@yandex.ru). 